\title{
Biodegradable bio-based plastics: Compostable or recyclable?
}

\author{
Tamás Tábi*iD
}

Department of Polymer Engineering, Faculty of Mechanical Engineering, Budapest University of Technology and Economics, H-1111 Budapest, Müegyetem rkp. 3., Hungary

MTA-BME Research Group for Composite Science and Technology, H-1111 Budapest, Mủegyetem rkp. 3., Hungary

In the last few decades, much attention has turned to bioplastics that are renewable resource-based and/or inherently biodegradable. Although plastics like biobased polypropylene (bio-PP) fulfill the definition of bioplastics, in this editorial, I will focus on bioplastics that are both bio-based and biodegradable, like polylactic acid (PLA). Currently, their production rate is increasing significantly day by day as more and more bio-refineries are builtall over the globe. As a result of the continuously increasing production and research applied to tailor their properties for various applications (https://doi.org/10.1016/j. polymertesting.2021.107282), these products are infiltrating our everyday lives imperceptibly. Although this is a forward-looking process, sometimes their use is criticized. Most criticism comes from the fact that these materials are often only referred to as biodegradable or compostable. Indeed, they can undergo biodegradation (https://doi.org/10.1016/j.wasman.2021.08.016) under certain conditions, like in industrial compost. Still, unfortunately, for those who are less knowledgeable in the area, the term 'biodegradable' may mean 'single-use' or 'disposable', and thus it is falsely believed that if they are thrown away, they will disappear in nature. Since they are called compostable, composting will be forced as an end-of-life option, although compostable does not mean 'only compostable'. The point is that composting is just one end-of-life option for bioplastics, but not the only one. These options include the ones readily available for ordinary petroleum-based plastics, like reuse or mechanical recycling (https://doi. org/10.1016/j.polymdegradstab.2019.109045). And ${ }^{*}$ Corresponding author, e-mail: tabi@pt.bme.hu
(C) BME-PT there is also the possibility of incineration, pyrolysis or chemical recycling (https://doi.org/10.1016/j. resconrec.2021.105670). To show the complete picture, instead of emphasizing only the compostable or biodegradable character of bioplastics, we should call them 'renewable resource-based (bio-based) as well as mechanically and chemically recyclable, reusable, combustible and compostable plastics'. Bio-based means that they are based on atmospheric $\mathrm{CO}_{2}$, which is chemically bound during photosynthesis (mostly into cellulose and/or starch), and thus during the production of bioplastics, this $\mathrm{CO}_{2}$ is conserved (https://doi.org/10.1016/j.jcomc.2021.100111). Since bioplastics can be produced from renewable resources, and there are various end-of-life options, their life cycle fits the idea of the circular economy perfectly. We borrow the raw materials from nature, use them as products permanently or repeatedly, and then return them to the environment. This is the main message and actual value of bioplastics: to use a product for as long as possible and recycle it with the methods mentioned above, and finally, when the quality of the material of the product does not meet the requirements any more, we can give nature back what we borrowed, using composting.

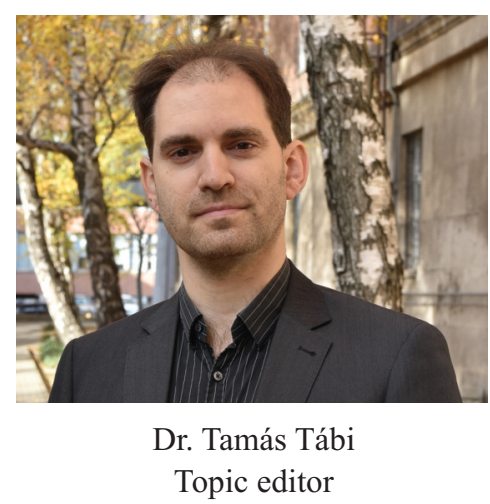

